\title{
INSTITUSI PENDIDIKAN PADA MASA DINASTI SALJUQ
}

\author{
Sy. Rohana
}

Sekolah Tinggi Agama Islam Negeri (STAIN) Teungku Dirundeng Meulaboh

Email: Syrohana6. gmail.com

\begin{abstract}
Abstrak
Dinasti Saljuq didirikan oleh Tughril Beg pada tahun 429 H / 1037 M. Pemerintahan Saljuq ini dikenal dengan nama al-Salajiqah al-Kubra (Saljuq Besar atau Saljuq Agung). Pemerintahan atau Dinasti Saljuq merupakan rangkaian sejarah Khalifah Abbasiyah. Dinasti Saljuq meraih tampuk kepemimpinan dan kekuasaan di lingkungan kekhalifahan Abbasiyah setelah menumbangkan kekuasaan Dinasti Buwaihi dan kekuasaannya berlangsung selama lebih kurang dari dua abad. Zaman kaum Saljuq banyak terjadi kebangkitan pikiran yang pesat, yang dasarnya telah dirintis oleh Nizamul Mulk wazir kepada Alb Arislan dan Maliksyah. Wazir yang berilmu pengetahuan ini telah mendirikan sekolah-sekolah yang menggunakan namanya, yaitu Nizamiyah. Sekolah-sekolah tersebut terdapat di tempat-tempat berikut: Baghdad, Balkh, Nisabur, Harat, Asfahan, Basrah, Marwu, Amal dan Mausil. Menurut asSubki, Nizamul Mulk mempunyai sekolah di setiap kota di Iraq dan khurasan.
\end{abstract}

Kata Kunci: Dinasti Saljuq, Khalifah Abbasiyah, instansi pendidikan

\begin{abstract}
Saljuq Dynasty was founded by Tughril Beg in 429 H/1037 AD. Its government was known as al-Salajiqah al-Kubra (the Great Saljuq or the Glorious Saljuq). The government or Saljuq Dynasty is part of the history of the Abbasiyah Dynasty. It reached its grand leadership and supreme power after they conquered the Buwaihi Dynasti. Their leadership lasted for approximately two centuries. In the era of Saljuq Dynasty there was a rapid rise and awakening of mind pioneered by Nizamul Mulk, the minister of Alb Arislan and Maliksyah. This knowledgeable minister had established a number of schools under his name, Nizamiyah. Those schools were located in many places which include Baghdad, Balkh, Nisabur, Harat, Asfahan, Basrah, Marwu, Amal and Mausil. According to as-Subki, Nizamul Mulk owned a school almost in many cities in Iraq and Khurassan.
\end{abstract}

Key words: Saljuq Dynasty, Abbasiyah Dynasty, educational institution

\section{PENDAHULUAN}

Pendidikan merupakan kebutuhan sepanjang hayat. Setiap manusia membutuhkan pendidikan, sampai kapan dan dimanapun ia berada. Pendidikan sangat penting artinya, sebab tanpa pendidikan manusia akan sulit berkembang dan bahkan akan terbelakang.
Dengan demikian pendidikan harus betul-betul diarahkan untuk menghasilkan manusia yang berkualitas dan mampu bersaing, di samping memiliki budi pekerti yang luhur dan moral yang baik.

Rasulullah SAW adalah pendidik pertama dan terutama dalam dunia pendidikan 
Islam. Proses trasformasi ilmu pengetahuan, internalisasi nilai-nilai spriritualisme, dan bimbingan emosional yang dilakukannya dapat dikatakan sebagai mu'jizat yang luar biasa, yang manusia di manapun tidak dapat melakukan hal yang sama. Maka kalau kita membaca sejarahsejarah perkembangan pendidikan Islam baik pada masa klasik maupun pada masa modern terjadi pasang surut. Hal ini dikarenakan setiap masa mengalami pembaharuan dalam berbagai komponen, sama halnya dengan Dinasti Saljuq dalam pemerintahannya dan kekuasaanny.

Pemerintahan atau Dinasti Saljuq merupakan rangkaian sejarah Khalifah Abbasiyah. Dinasti Saljuq meraih tampuk kepemimpinan dan kekuasaan di lingkungan kekhalifahan Abbasiyah setelah menumbangkan kekuasaan Dinasti Buwaihi, dan kekuasaannya berlangsung selama lebih kurang dari dua abad.

Priode Saljuq ini, menurut hemat penulis, cukup menarik untuk dibahas dan dikaji serta diteliti secara mendalam sehingga kita dapat mengetahui bagaimana kiprahnya dalam kepemimpinan dan kekuasaannya. Setidaknya ada dua hal yang bisa dikemukakan sebagai alasan, yaitu:

1. Periode ini telah lahir Imam al-Ghazali, seorang ulama besar dan kenamaan yang akan mempengaruhi jalan sejarah umat Islam pada masa berikutnya terutama di dunia Islam belahan timur yang mayoritas beraliran Sunni. Dari sudut pandang sejarah peradaban Islam cukup menarik untuk dikaji dan diteliti.

2. Priode ini merupakan Priode kekhalifahan Abbasiyah yang terakhir. Tanda-tanda kemunduran kekhalifahan Abbasiyah mulai tampak kelihatan. Puncak dari kemunduran adalah jatuhnya kota Baghdad ke tangan bangsa Mongol.

Zaman kaum Saljuq banyak terjadi kebangkitan pikiran yang pesat, yang dasarnya telah dirintis oleh Nizamul Mulk wazir kepada Alb Arislan dan Maliksyah. Wazir yang berilmu pengetahuan ini telah mendirikan sekolahsekolah yang menggunakan namanya, yaitu Nizamiyah. Sekolah-sekolah tersebut terdapat di tempat-tempat beriku: Baghdad, Balkh, Nisabur, Harat, Asfahan, Basrah, Marwu, Amal dan Mausil. Menurut as-Subki, Nizamul Mulk mempunyai sekolah di setiap kota di Iraq dan khurasan. ${ }^{1}$

Disamping itu Nizamul Mulk juga telah memberikan perlindungan yang secukupnya kepada para cerdik pandai di zamannya, seperti Imam Al-Ghazali yang sangat terkenal di bidang ilmu-ilmu Islam, tasawuf dan falsafah juga merupakan tenaga pengajar sekolah Fatimiyah yang paling cemerlang.

\section{SEKILAS TENTANG DINASTI SALJUQ}

Dinasti Saljuq didirikan oleh Tughril Beg pada tahun 429 H / 1037 M. Pemberitahuan pendirian dinasti ini dilakukannya segera setelah kaum Saljuq mengalahkan kaum Ghaznah pada tahun yang sama. Setelah kedudukan Dinasti Saljuq menjadi kuat dan solid, barulah diiktirafkan oleh khalifah Abbasiyah pada tahun $432 \mathrm{H}$

Kekaisaran Saljuq Raya atau Kekaisaran Saljuq Agung adalah imperium Islam Sunni abad pertengahan yang pernah menguasai wilayah (Jakarata : Pustaka Al-Husna ,1993), h. 351. 
dari Hindu Kush sampai Anatolia timur dan dari Asia Tengah sampai Teluk Persia. Dari tempat awal mereka di Laut Aral, Saljuq bergerak pertama ke Khorasan dan lalu ke Persia daratan sebelum menguasai Anatolia timur. Kekaisaran ini didirikan oleh Dinasti Saljuq.

Jatuhnya kekuasaan Bani Buwaih ke tangan Saljuq Ibn Tuqaq bermula dari perebutan kekuasaan di dalam negeri. Ketika al-Malik al- Rahim memegang jabatan Amir al-Umara, kekuasaan itu dirampas oleh panglimanya sendiri, Arselan al-Basasiri. Dengan kekuasaan yang ada di tangannya, al-Basasiri berbuat sewenang-wenang terhadapap Al-Malik alRahim dan Khalifah al-Qaimdari Bani Abbas; bahkan dia mengundang khalifah Fathimiyah, (al-Mustanshir, untuk menguasai Baghdad. Hal ini mendorong khalifah meminta bantuan kepada Tughril Bek Rahimahullah dari daulah Bani Saljuq yang berpangkalan di negeri Jabal. Pada tanggal 18 Desember 1055 M/447 $\mathrm{H}$ pimpinan Saljuq itu memasuki Baghdad. Al-Malik al-Rahim, Amir al-Umara Bani Buwaih yang terakhir, dipenjarakan. Dengan demikian berakhirlah kekuasaan Bani Buwaih dan bermulalah kekuasaan Daulah Saljuq. Pergantian kekuasaan ini juga menandakan awal periode keempat khilafah Abbasiyah. Bani Saljuq berasal dari beberapa kabilah kecil rumpun suku Ghuz di wilayah Turkistan. Pada abad kedua, ketiga, dan keempat Hijrah mereka pergi ke arah barat menuju Transoxiana dan Khurasan. Ketika itu mereka belum bersatu. Mereka dipersatukan oleh Saljuq ibn Tuqaq. Karena itu, mereka disebut orang-orang Saljuq. Pada mulanya Saljuq ibn Tuqaq Rahimahullah mengabdi kepada Bequ, raja daerah Turkoman yang meliputi wilayah sekitar laut Arab dan laut Kaspia. Saljuq Rahimahullah diangkat sebagai pemimpin tentara. Pengaruh Saljuq Rahimahullah sangat besar sehingga Raja Bequ khawatir kedudukannya terancam. Raja Bequ bermaksud menyingkirkan Saljuq.

Namun sebelum rencana itu terlaksana, Saljuq Rahimahullah mengetahuinya. Ia tidak mengambil sikap melawan atau memberontak, tetapi bersama pengikutnya ia bermigrasi ke daerah land, atau disebut juga Wama Wara'a al-Nahar, sebuah daerah muslim di wilayah Transoxiana (antara sungai Ummu Driya dan Syrdarya atau Sihun). Mereka mendiami daerah ini atas izin penguasa daulah Samaniyah yang menguasai daerah tersebut. Mereka masuk Islam dengan manhaj Sunni Salafy. Ketika daulah Samaniyah dikalahkan oleh daulah Ghaznawiyah, Saljuq Rahimahullah menyatakan memerdekakan diri. Ia berhasil menguasai wilayah yang sebelumnya dikuasai oleh daulah Samaniyah.

\section{Setelah Saljuq Rahimahullah}

meninggal, kepemimpinan dilanjutkan oleh anaknya, Israil Ibn Saljuq dan kemudian penggantinya Mikail Ibn Israil Ibn Saljuq, namun sayang saudaranya dapat ditangkap oleh penguasa Ghaznawiyah. Kepemimpinan selanjutnya dipegang oleh Thugril Bek Rahimahullah. Pemimpin Saljuq terakhir ini berhasil mengalahkan Mas'ud al-Ghaznawi, penguasa dinasti Ghaznawiyah, pada tahun 429 H/1036 M, dan memaksanya meninggalkan daerah Khurasan. Setelah keberhasilan tersebut, Thugril memproklamasikan berdirinya daulah Saljuq. Pada tahun 432 H/1040 M daulah ini mendapat pengakuan dari khalifah Abbasiyah di Baghdad. Di saat kepemimpinan Thugril Bek inilah, dinasti Saljuq memasuki 
Baghdad menggantikan posisi Bani Buwaih. Sebelumnya, Thugril Rahimahullah berhasil merebut daerah-daerah Marwadan Naisabur dari kekuasaan Ghaznawiyah, Balkh, urjan, Tabaristan, Khawarizm, Rayy, dan Isfahan.

Posisi dan kedudukan khalifah lebih baik setelah dinasti Saljuq berkuasa; paling tidak kewibawaannya dalam bidang agama dikembalikan setelah beberapa lama "dirampas" orang-orang Syi'ah. Meskipun Baghdad dapat dikuasai, namun ia tidak dijadikan sebagai pusat pemerintahan. Thugrul Bek Rahimahullah memilih kota Naisabur dan kemudian kota Rayy sebagai pusat pemerintahannya. Daulahdaulah kecil yang sebelumnya memisahkan diri, setelah ditaklukkan daulah Saljuq ini, kembali mengakui kedudukan Baghdad, bahkan mereka terus menjaga keutuhan dan keamanan Abbasiyah untuk membendung faham Syi'ah dan mengembangkan manhaj Sunni Salafy yang dianut mereka.

Sepeninggal Thugril Bek Rahimahullah (455 H/1063 M), daulah Saljuq berturut-turut diperintah oleh :

1. Alp Arselan Rahimahullah (455-465 H/1063-1072),

2. Maliksyah (465-485 H/1072-1092),

3. Mahmud Al-Ghazi (485-487 H/1092$1094 \mathrm{M})$,

4. Barkiyaruq (487 -498 H/1 094-1103),

5. Maliksyah II $(498 \mathrm{H} / 1103 \mathrm{M})$,

6. Abu Syuja' Muhammad (498-511 H/11 03-1117 M),dan

7. Abu Harits Sanjar (511-522H/1117$1128 \mathrm{M}){ }^{2}$

2

http: /id, wiki pedia , org / wiki/ berkas : Saljuq Emperilocator-map.svg, diunduh tanggal 2 Januari 2017.
Pemerintahan Saljuq ini dikenal dengan nama al-Salajiqah al-Kubra (Saljuq Besar atau Saljuq Agung). Disamping itu, ada beberapa pemerintahan Saljuq lainnya di beberapa daerah sebagaimana disebutkan terdahulu. Pada masa Alp Arselan Rahimahullah perluasan daerah yang sudah dimulai oleh Thugril Bek Rahimahullah dilanjutkan ke arah barat sampai pusat kebudayaan Romawi di Asia Kecil, yaitu Bizantium. Peristiwa penting dalam gerakan ekspansi ini adalah apa yang dikenal dengan peristiwa Manzikert. Tentara Alp Arselan Rahimahullah berhasil mengalahkan tentara Romawi yang besar yang terdiri dari tentara Romawi, Ghuz, al-Akraj, al-Hajr, Perancis, dan Armenia. Dengan dikuasainya Manzikert tahun $1071 \mathrm{M}$ itu, terbukalah peluang baginya untuk melakukan gerakan penturkian (turkification) di Asia Kecil. Gerakan ini dimulai dengan mengangkat Sulaiman ibn Qutlumish, keponakan Alp Arselan, sebagai gubernur di daerah ini. Pada tahun $1077 \mathrm{M}$ $(470 \mathrm{H})$, didirikanlah kesultanan Saljuq Ruum dengan ibu kotanya Iconim. Sementara itu putera Arselan, Tutush Rahimahullah, berhasil mendirikan dinasti Saljuq di Syria pada tahun 1094 M/487 H.

Pada masa Sulthan Maliksyah wilayah kekuasaan Daulah Saljuq ini sangat luas, membentang dari Kashgor, sebuah daerah di ujung daerah Turki, sampai ke Yerussalem. Wilayah yang luas itu dibagi menjadi lima bagian:

1. Saljuq Besar yang menguasai Khurasan, Rayy, Jabal, Irak, Persia, dan Ahwaz. Ia merupakan induk dari yang lain. Jumlah Syekh yang memerintah seluruhnya delapan orang. 
2. Saljuq Kirman berada di bawah kekuasaan keluarga Qawurt Bek ibn Dawud ibn Mikail ibn Saljuq. Jumlah syekh yang memerintah dua belas orang.

3. Saljuq Iraq dan Kurdistan, pemimpin pertamanya adalah Mughirs al Din Mahmud.

Saljuq ini secara berturut-turut diperintah oleh sembilan syekh.

4. Saljuq Syria, diperintah oleh keluarga Tutush ibn Alp Arselan ibn Daud ibn Mikail ibn Saljuq, jumlah syekh yang memerintah lima orang.

5. Saljuq Rum, diperintah oleh keluarga Qutlumish ibn Israil ibn Saljuq dengan jumlah syeikh yang memerintah seluruhnya 17 orang.

Disamping membagi wilayah menjadi lima, dipimpin oleh gubernur yang bergelar Syeikh atau Malik itu, penguasa Bani Saljuq juga mengembalikan jabatan perdana menteri yang sebelumnya dihapus oleh penguasa Bani Buwaih. Jabatan ini membawahi beberapa departemen. Pada masa Alp Arselan Rahimahullah, ilmu pengetahuan dan agama mulai berkembang dan mengalami kemajuan pada zaman Sultan Maliksyah yang dibantu oleh perdana menterinya Nizham al-Mulk. Perdana menteri ini memprakarsai berdirinya Universitas Nizhamiyah (1065 M) dan Madrasah Hanafiyah di Baghdad. Hampir di setiap kota di Irak dan Khurasan didirikan cabang Nizhamiyah. Menurut Philip K. Hitti, Universitas Nizhamiyah inilah yang menjadi model bagi segala perguruan tinggi di kemudian hari. Perhatian pemerintah terhadap perkembangan ilmu pengetahuan melahirkan banyak ilmuwan muslim pada masanya. Di antara mereka adalah
az-Zamakhsyari dalam bidang tafsir, bahasa, dan teologi; al-Qusyairy dalam bidang tafsir; Abu Hamid al-Ghazali Rahimahullah dalam bidang teologi; dan Farid al-Din al-'Aththar dan Umar Khayam dalam bidang sastra.Bukan hanya pembangunan mental spiritual, dalam pembangunan fisik pun dinasti Saljuq banyak meninggalkan jasa. Maliksyah terkenal dengan usaha pembangunan di bidang yang terakhir ini. Banyak masjid, jembatan, irigasi dan jalan raya dibangunnya.

Setelah Sultan Maliksyah dan perdana menteri Nizham al-Mulk wafat, Saljuq Besar mulai mengalami masa kemunduran di bidang politik. Perebutan kekuasaan di antara anggota keluarga timbul. Setiap propinsi berusaha melepaskan diri dari pusat. Konflik-konflik dan peperangan antar anggota keluarga melemahkan mereka sendiri. Sementara itu, beberapa dinasti kecil memerdekakan diri, seperti Syahat Khawarizm, Ghuz, dan al-Ghuriyah. Pada sisi yang lain, sedikit demi sedikit kekuasaan politik khalifah juga kembali, terutama untuk negeri Irak. Kekuasaan dinasti Saljuq di Irak berakhir di tangan Khawarizm Syah pada tahun $590 \mathrm{H} /$ 1199 M. ( Wallahul Musta'an ). ${ }^{3}$

Pada Masa Kesultanan Saljuq inilah, sistem asuransi pertama diperkenalkan. Kesultanan Saljuq akan membayar semua kerugian dari pedagang yg mengalami peristiwa perampokan di dalam teritori Saljuq.

Sultan yang memerintah pada Dinasti Saljuq adalah :

1. Thugril Bek Rahimahullah (455 H/1063 M),

2. Alp Arselan Rahimahullah (455-465 3

http:/id,wiki pedia,org/ Kesultanan, Saljuq raya \# citenote-0, diunduh tanggal 2Januari 2017. 
H/1063-1072),

3. Maliksyah (465-485 H/1072-1092),

4. Mahmud Al-Ghazi (485-487 H/10921094 M),

5. Barkiyaruq (487 -498 H/1 094-1103),

6. Maliksyah II (498 H/ 1103 M),

7. Abu Syuja' Muhammad (498-511 H/11 03-1117 M),dan

8. Abu Harits Sanjar (511-522H/1117$1128 \mathrm{M}) .^{4}$

Keberhasilan Dinasti Saljuq mempertahankan kekuasaannya selama kira-kira dua abat lamanya tak terlepas dari peranan para pejabat/ wazir/ menteri yang ada di lingkungan pemerintahannya . Diantara wazir-wazir yang terkenal pada masa itu adalah :

1. Abu Nasr Muhammad bin Muhammad Fakhrul Daulah bin Juhair, wazir pada masa al-Qa'im.

2. Abu Syarwan bin Khalid al-Qasyani, wazir pada masa al- Mustarsyid.

3. Ibn al-'Attar, wazir pada masa al-Nasir .

4. Abu Nasr Muhammad bin Mansur alKundari, wazir Sultan Tughrul Beg dan Sultan Alb Arsalan.

5. Taju al-Din Abu al-Ghanayim, wazir Sultan Sanjar .

6. Ali bin al-Hasan al-Tugha'i, wazir Sultan Sanjar.

7. Sa'ad bin Ali Isa, wazir Sultan mas'ud bin muhammad di Irak

8. Nizam al-Mulk, wazir Sultan Alb Arsalan dan Sultan malik Syah. ${ }^{5}$

4

http:/id, wiki pedia,org/ Kesultanan, Saljuq raya \# citenote-0,dinuduh tanggal 2 Januari 2017

5

Suwito,et al, Sejarah Sosial Pendidikan Islam, ( Jakarta : Kencana , 2005 ), h. 149.

54 | BIDAYAH: Volume 11, No. 1, Juni 2020

\section{PENDIDIKAN ISLAM}

Pendidikan memiliki peran penting, karena tanpa melalui pendidikan proses transformasi dan aktualisasi pengetahuan moderen sulit untuk diwujudkan. Demikian halnya dengan sains sebagai bentuk pengetahuan ilmiah dalam pencapaiannya harus melalui proses pendidikan yang ilmiah pula. Yaitu melalui metodologi dan kerangka keilmuan yang teruji. Karena tanpa melalui proses ini pengetahuan yang didapat tidak dapat dikatakan ilmiah.

Dalam Islam pendidikan tidak hanya dilaksanakan dalam batasan waktu tertentu saja, melainkan dilakukan sepanjang usia (long life education). Islam memotivasi pemeluknya untuk selalu meningkatkan kualitas keilmuan dan pengetahuan. Tua atau muda, pria atau wanita, miskin atau kaya mendapatkan porsi sama dalam pandangan Islam dalam kewajiban untuk menuntut ilmu (pendidikan). Bukan hanya pengetahuan yang terkait urusan $u k h r o w i$ saja yang ditekankan oleh Islam, melainkan pengetahuan yang terkait dengan urusan duniawi juga. Karena tidak mungkin manusia mencapai kebahagiaan hari kelak tanpa melalui jalan kehidupan dunia ini.

Islam juga menekankan akan pentingnya membaca, menelaah, meneliti segala sesuatu yang terjadi di alam raya ini. Membaca, menelaah, meneliti hanya bisa dilakukan oleh manusia, karena hanya manusia makhluk yang memiliki akal dan hati. Selanjutnya dengan kelebihan akal dan hati, manusia mampu memahami fenomena-fenomena yang ada di sekitarnya, termasuk pengetahuan. Dan sebagai implikasinya kelestarian dan keseimbangan alam harus dijaga sebagai bentuk tugas manusia 
sebagai khalifah fil ardh.

Dari sini dapat dipahami betapa pentingnya pengetahuan bagi kelangsungan hidup manusia. Karena dengan pengetahuan manusia akan mengetahui apa yang baik dan yang buruk, yang benar dan yang salah, yang membawa manfaat dan yang membawa madharat.

Islam menekankan akan pentingnya pengetahuan dalam kehidupan manusia. Karena tanpa pengetahuan niscaya manusia akan berjalan mengarungi kehidupan ini bagaikan orang tersesat, yang implikasinya akan membuat manusia semakin terlunta-lunta kelak di hari akhirat.

Pendidikan Islam memiliki karakteristik yang berkenaan dengan cara memperoleh dan mengembangkan pengetahuan serta pengalaman. Anggapan dasarnya ialah setiap manusia dilahirkan dengan membawa fitrah serta dibekali dengan berbagai potensi dan kemampuan yang berbeda dari manusia lainnya. Dengan bekal itu kemudian dia belajar: mulamula melalui hal yang dapat diindra dengan menggunakan panca indranya sebagai jendela pengetahuan; selanjutnya bertahap dari halhal yang dapat diindra kepada yang abstrak, dan dari yang dapat dilihat kepada yang dapat difahami. Sebagaimana hal ini disebutkan dalam teori empirisme dan positivisme dalam filsafat. Dalam firman Allah Q.s. an-Nahl ayat 78 disebutkan:

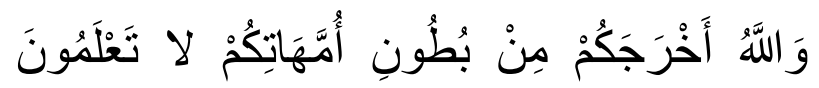

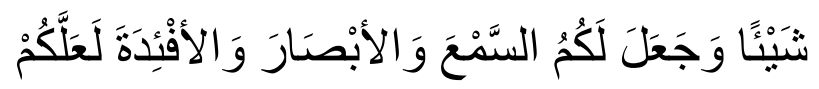

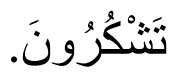

"Dan Allah mengeluarkan kamu dari perut ibumu dalam keadaan tidak mengetahui sesuatupun, dan Dia memberi kamu pendengaran, penglihatan, dan hati agar kamu bersyukur".

Dengan pendengaran, penglihatan dan hati, manusia dapat memahami dan mengerti pengetahuan yang disampaikan kepadanya, bahkan manusia mampu menaklukkan semua makhluk sesuai dengan kehendak dan kekuasaannya.

$$
\text { Al-Qur'an telah berkali-kali }
$$
menjelaskan akan pentingnya pengetahuan. Tanpa pengetahuan niscaya kehidupan manusia akan menjadi sengsara. Tidak hanya itu, alQur'an bahkan memposisikan manusia yang memiliki pengetahuan pada derajat yang tinggi. Al-Qur'an surat al-Mujadalah ayat 11 menyebutkan:

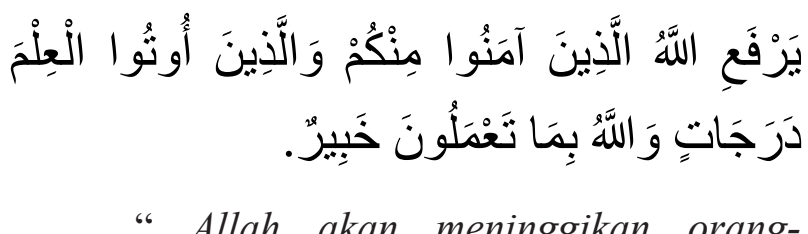
orang yang beriman di antaramu dan orangorang yang diberi ilmu pengetahuan beberapa derajat. Dan Allah Maha Mengetahui apa yang kamu kerjakan.

Al-Qur'an juga telah memperingatkan manusia agar mencari ilmu pengetahuan, sebagaimana dalam al-Qur'an surat at-Taubah ayat 122 disebutkan:

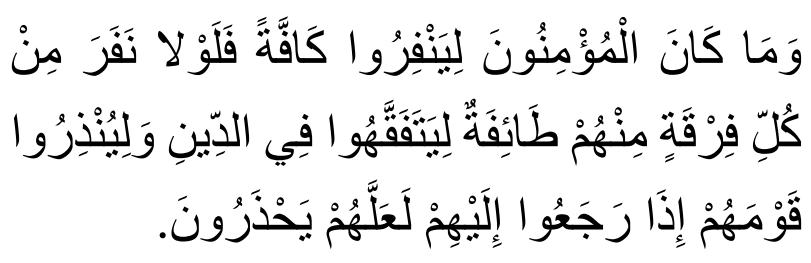


Artinya: Tidak sepatutnya bagi orang-orang yang mukmin itu pergi semuanya (ke medan perang). Mengapa tidak pergi dari tiap-tiap golongan di antara mereka beberapa orang untuk memperdalam pengetahuan mereka tentang agama dan untuk memberi peringatan kepada kaumnya apabila mereka telah kembali kepadanya, supaya mereka itu dapat menjaga dirinya.

Dalam sebuah sabda Nabi saw. dijelaskan:

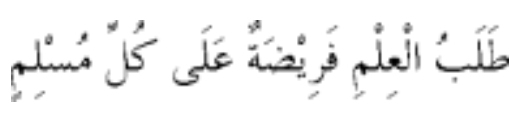

"Mencari ilmu adalah kewajiban setiap muslim". (HR. Ibnu Majah)

Hadits tersebut menunjukkan bahwa Islam mewajibkan kepada seluruh pemeluknya untuk mendapatkan pengetahuan. Yaitu, kewajiban bagi mereka untuk menuntut ilmu pengetahuan.

Imam Syafi'i pernah menyatakan:

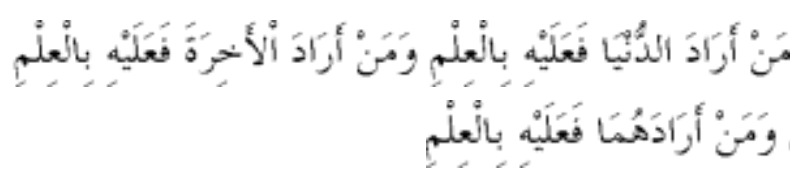

"Barangsiapa menginginkan dunia, maka harus dengan ilmu. Barangsiapa menginginkan akhirat, maka harus dengan ilmu. Dan barangsiapa menginginkan keduanya, maka harus dengan ilmu".

Dari sini, sudah seyogyanya manusia selalu berusaha untuk menambah kualitas ilmu pengetahuan dengan terus berusaha mencarinya hingga akhir hayat.
Dalam al-Qur'an surat Thahaa ayat 114 disebutkan:

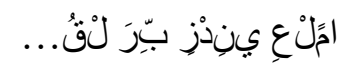

Artinya: ...Katakanlah: Ya Tuhanku, tambahkanlah kepadaku ilmu pengetahuan.

Pemanfaatan pengetahuan harus ditujukan untuk mendapatkan kemanfaatan dari pengetahuan itu sendiri, menjaga keseimbangan alam semesta ini dengan melestari-kan kehidupan manusia dan alam sekitarnya, yang sekaligus sebuah aplikasi dari tugas kekhalifahan manusia di muka bumi. Dan pemanfaatan pengetahuan adalah bertujuan untuk ta'abbud kepada Allah swt., Tuhan semesta alam.

Manusia adalah makhluk yang memiliki tanggung jawab, yaitu tanggung jawab menjadi khalifah fil ardh. Kekhalifahan manusia adalah salah satu bentuk dari ta'abbud-nya kepada sang Khalik. Sedangkan ta'abbud adalah tugas pokok dari penciptaan manusia, sekaligus menggali, mengatur, menjaga dan memelihara alam semesta ini. ${ }^{6}$

\section{INSTITUSI PENDIDIKAN YANG DOMINAN PADA MASA DINASTI SALJUQ.}

Sebelum berdirinya madrasah, kaum muslimin pada masa itu sudah mengenal beberapa institusi pendidikan, yaitu Mesjid,

6

http: /hasanrizal.wordpress,com/2009/10/21/tafsir tarbawi-pendidikan-dalam-perspektif al-qur \%/ E2/80\%/99an, diunduh tanggal 2 Januari 2017 
Kuttab, Toko Buku, rumah dan lain-lain. ${ }^{7}$

Madrasah, menurut sebahagian ahli sejarah, pertama kali dikenal di dunia Islam pada masa Dinasti Saljuq. Penggagas berdirinya adalah salah seorang diri wazir terkenal Dinasti Saljuq yang bernama Nizam al-Mulk (465$485 \mathrm{H}$ ). Ia hidup dan menjadi wazir pada masa pemerintahan Sultan Alb Arsalan dan Sultan Malik Syah. Madrasah- madrasah itu didirikan di berbagai kota di dalam wilayah kekuasaan Dinasti Saljuq seperti Baghdad, Nisapur, Balk, Heart, Asfahan, Basrah, Marwu, Annal dan Mausil. Menurut al-Subki, seperti dikutip oleh Syalabi, bahwa Nizam al-Mulk mempunyai madrasah di setiap kota di Irak dan Khurasan. Madrasah-madrasah itu diberi nama Nizamiyyah sesuai dengan nama pendirinya. ${ }^{8}$

Dan kita ketahui pula bahwa pendidikan adalah sebuah aktivitas sosial yang harus ada ditengah-tengah masyarakat, masyarakat sebagai objek yang sekaligus sebagai subjek pendidikan dari waktu kewaktu secara terus menerus bertambah jumlahnya. Maka dengan bertambah anggota masyarakat otomatis akan meningkatkan pula kebutuhan dan tuntutan kehidupan yang harus dipenuhi, dengan demikian kebutuhan terhadap pendidikan bukan lagi persoalan individual tetapi sudah merupakan persoalan secara umum, bila sudah menjadi persoalan umum tentu dicarikan lembaga pendidikan yang memenuhi tuntutan

7

Lihat, Ahmad Syalabi, History of Muslim Education (Bairud: Dar al-Kashshaf, 19540),h. 1. Ahmad Syalabi menjelaskan lebih lanjud bahwa tahun $495 \mathrm{H}$ merupakan tonggak sejarah penting dalam sejarah pendidikan Islam karena saat itu madrasah mulai diperkenalkan di dunia Islam sehingga sejarah pendidikan Islam itu menjadi periode sebelum madrasah dan sebuah madrasah .

8

Suwito, Sejarah Sosial Pendidikan Islam,... h. 150. tersebut . Lembaga yang bentuknya bagaimana? salah satunya adalah madrasah pada saat itu merupakan lembaga atau institusi yang representatif untuk memenuhi tuntutan dan kebutuhan terhadap pendidikan.

Dinasti Saljuq (447-656 H/1055-1258 M) memiliki wilayah kekuasaan yang sangat luas. Masyarakat yang berada di wilayahnya tentu jumlahnya banyak pula. Mereka memiliki latar belakang yang berbeda -beda; agama, suku bangsa, sosial, dan budaya. Walaupun berbeda-beda, merka adalah rakyat yang menetap di dalam wilayah kekuasaan Dinasti Saljuq. Mereka harus disantuni dan dipenuhi seluruh kebutuhannya termasuk kebutuhan pendidikannya. Bagaimanakah caranya agar kebutuhan pendidikan dari masyarakat yang banyak jumlahnya dan cukup beragam dari sisi latar belakang sosial budayanya? Tentunya madrasah merupakan institusi alternatif untuk mengatasi persoalan pendidikan seperti itu.

Tentang motif pendirian madrasah, Ahmad Syalabi, salah seorang pakar sejarah pendidikan Islam, menjelaskan bahwa pendirian madrasah pada masa Dinasti Saljuq itu merupakan konsekwensi logis dari pertambahan jumlah murid atau peserta didik pada masa pertumbuhan dan perkembangan Islam. Karena murid terus bertambah maka sistim pendidikan pun harus berubah, dari perhatiannya yang cenderung dan berorientasi individual menjadi cenderung dan berorientasi missal. ${ }^{9}$

Dari penjelasan diatas, dapat kita pahami bahwa pendirian Madrasah Nizamiyyah pada zaman Nizam al Mulk untuk memenuhi dan motivasinya agar kebutuhan masyarakat 9

Ahmad Syalabi, History of Muslim Education, ...h. 55. 
terhadap pendidikan yang semakin luas.

Pendirian Madrasah Nizamiyyah itu, disamping memiliki motif pendidikan, juga memiliki motif atau kepentingan politik Dinasti Saljuq sendiri pada saat itu. Dinasti Buwaihi, yang menguasai kekhalifahan Abbasiyah saat itu dan kemudian ditaklukkan oleh Dinasti Saljuq, menganut aliran keagamaan Syi'i dan berusaha menanamkan pengaruh aliran itu di tengahtengah masyarakatnya melalui propaganda termasuk melalui aktivitas pendidikan. Dinasti Saljuq sendiri menganut aliran keagamaan Sunni. Aliran Sunni dan Syi'i memiliki doktrin atau idiologi politik yang berbeda. Bagaimana caranya agar pengaruh aliran Syi'i peninggalan Dinasti Buwaihi yang ada ditengah-tengah masyarakat itu menjadi berkurang atau lenyap sama sekali? Untuk mengatasinya, Dinasti Saljuq melakukan propaganda tandingan. Salah satunya melalui institusi pendidikan madrasah. Karena itu madrasah didirikan di seluruh wilayah kekhalifahan Abbasiyah yang dikuasai oleh Dinasti Saljuq. Sebagai contoh, Universitas Nizamiyyah di Baghdad didirikan untuk menandingi Universitas al-Azhar di Kairo yang di kuasai oleh Dinasti Fatimiyyah yang beraliran Syi'ah. ${ }^{10}$

Selain kepentingan politis-idiologis adakah kepentingan lain dari pendirian madrasah tersebut? priode Dinasti Saljuq dalam kekhalifahan Abbasiyah merupakan awal mula masuknya pengaruh kebudayaan Turki; sebelumnya kekhalifahan Abbasiyah pernah di pengaruhi oleh kebudayaan Arab dan Persia; ke dalam kekhalifahan Abbasiyah .Keterlibatan pemerintah dengan berbagai kepentingannya dalam aktivitas pendidikan merupakan fenomena yang menarik dari Dinasti Saljuq. Institusi pendidikan yang bernama madrasah ini memang cukup fenomenal pada masa ini. Madrasah didirikan secara besar-besaran di seluruh penjuru negeri terutama di kota-kota yang menjadi titik pusat perkembangan peradaban waktu itu seperti Baghdad, Nisapur, Balk dan lainnya. Ada beberapa alasan Dinasti Saljuq mendirikan madrasah-madrasah diantaranya:

1. Untuk mengambil hati rakyat.

Para pembesar Turki yang berkuasa dalam Dinasti Saljuq terutama dalam lapangan militer, mereka bukan bangsa Arab dan bukan turunan Nabi Muhammad SAW, bagaimanakah caranya agar masyarakat bisa simpati dan memberi dukungan kepada pemerintah? Salah satu caranya adalah dengan jalan memajukan agama dan mendukung aktivitas pendidikan untuk masyarakatnya. Perwujudan dari keinginan ini adalah didirikannya madrasah di berbagai tempat seperti; di Baghdad (oleh Nizam Mulk dan Addud-Daulah), di Mesir (oleh Ibn Thulun dan Shalahuddin), di Siria (oleh Nuruddin), dan sebagainya.

2. Untuk mengharapkan pahala dan ampunan dari Allah SWT.

Para pejabat pemerintah saat itu telah banyak melakukan penyimpangan. Mereka, dengan kekuasaan dan kekayaan yang ada ditangannya, bukan melakukan 
pengayoman dan pelayanan kepada masyarakatnya melainkan hanya hidup berpesta pora dan bermewah-mewahan. Karena itu mereka beramal menyiarkan agama dengan mendirikan madrasahmadrasah untuk kepentingan pendidikan masyarakat. Dengan cara ini mereka berharap mendapat ampunan dan keridhaan Allah SWT.

3. Untuk memelihara kehidupan anaknya di kemudian hari

Para pejabat Turki yang menjadi wali dalam satu wilayah telah menjadi kaya raya dengan hasil bumi dan kekayaan yang dipungut dalam wilayahnya. Mereka khawatir, kalau mereka maati harta kekayaan mereka itu diambil begitu saja oleh sultan sehingga anak-anak keturunan mereka menjadi terlantar dan miskin. Oleh karenanya, mereka waqafkan harta kekayaannya. Di antara syarat waqaf itu adalah mereka tetapkan bahwa pengurus (nazir) waqaf itu adalah anak mereka sendiri, turun temurun sampai kepada anak cucunya dengan mendapat bagian yang tertentu dari waqaf itu. Dengan demikian terjaminlah kehidupan anak-anak mereka dan cucunya karena harta waqaf itu tidak dapat diganggugugat oleh siapapun juga.

4. Untuk memperkuat aliran keagamaan pemerintah

Pada masa itu telah timbul aliran-aliran keagamaan yang saling bertentangan seperti Syi'i dan Sunni. Orang-orang Turki yang menguasai kekhalifahan Abbasiyah menganut aliran Sunni. Agar kekuasaan mereka itu tetap bertahan tentunya harus ditopang oleh idiologi yang dianut oleh pemerintah. Karena itu didirikanlah madrasah-madrasah sebagai alat propaganda dan indoktrinasi idiologi di dalam wilayah-wilayah yang dikuasai oleh orang-orang Turki Saljuq ini. ${ }^{11}$

Dari pembahasan diatas dapat kita pahami bahwa tampak sekali motif pendirian madrasah pada masa Dinasti Saljuq ini sangat sarat dengan kepentingan pemerintah atau penguasa pada saat itu. Kepentingan politisidiologis penguasa tampaknya sangat dominan disamping kepentingan kependidikan agama dan kepentingan pribadi para penguasa Dinasti Saljuq.

\section{MATERI PENDIDIKAN DAN KURIKULUM YANG DIBERIKAN DALAM LEMBAGA PENDIDIKAN.}

Diantara institusi pendidikan yang sangat dominan pada saat Dinasti Saljuq adalah Madrasah. Pendirian madrasah pada saat itu tidak terlepas dari kepentingan politik yang mengitarinya. Madrasah oleh Dinasti Saljuq dijadikan alat propaganda tandingan untuk menekan pengaruh aliran Syi'i dan menyebarluaskan aliran Sunni di tengah-tengah masyarakat di seluruh wilayah kekuasaan Dinasti saljuq dengan cara memasukkan materi keagamaan versi Sunni kedalam kurikulum Madrasah Nizamiyyah. Sehingga cukup 11

Mahmud Yunus, Sejarah Pendidikan Islam, (Jakarta: Hidakarya Agung, 1992), h. 69. 
beralasan mengapa materi keagaan culup mendominasi dalam kurikulum pendidikan madrasah saat itu. ${ }^{12}$

Sebagai bukti dominasi ilmu-ilmu keagamaan dalam madrasa juga terbukti dari dokumen waqaf Madrasah Nizamiyyah, yaitu:

1. Nizamiyyah merupakan waqaf yang disediakan untuk kepentingan penganut mazhab Syafi'i dalam fikih dan ushul fikih

2. Harta benda yang diwaqafkan kepada Nizamiyyah adalah untuk kepentingan penganut mazhab Syafi'i dalam fikih dan ushul fikih

3. Pejabat-pejabat utama Nizamiyyah harus bermazhab Syafi'i dalam fikih dan ushul fikih; ini mencakup mudarris, wa'idh dan pustakawan

4. Nizamiyyah harus mempunyai seorang tenaga pengajar bidang kajian Al-Qur'an

5. Nizamiyyah harus mempunyai seorang tenaga pengajar bahasa Arab

6. Setiap staf menerima bagian tertentu dari penghasialan yang diperoleh dari harta waqaf nizamiyyah. ${ }^{13}$

Karena motif utama adalah politik dan idiologi maka Madrsah Nizamiyyah tidak memasukkan ilmu-ilmu kealaman (fisika, kimia dan astronomi) kedalam kurikulum pendidikan Islam. Ada kemungkinan, materi tersebut tidak dimasukkan kedalam kurikulum di Madrasah Nizamiyyah karena memang tidak begitu di

Ahmad Syalabi, History of Muslim Education,...h. 56. 13

Suwito, Sejarah Sosial Pendidikan Islam, ...h. 155.

60 | BIDAYAH: Volume 11, No. 1, Juni 2020 perlukan dalam kerangka kepentingan idiologi dan politik penguasa pada waktu itu.

Menurut Mahmud Yunus, rencana pengajaran di Madrasah Nizamiyyah pada saat tidak deketahui dengan jelas. namun bisa dikatakan bahwa kurikulum Madrasah Nizamiyyah pada saat itu di dominasi oleh ilmu-ilmu keagamaan atau ilmu-ilmu syari'ah. Buktinya adalah:

1. Tidak ada seorang pun ahli-ahli sejarah yang mengatakan bahwa diantara materi pelajaran yang diajarkan di Madrasah Nizamiyyah adalah ilmu kedokteran, ilmu falak, dan ilmu pasti. Tetapi mereka hanya menyebutkan bahwa diantara materi pelajarannya adalah nahwu, ilmu kalam, dan ilmu fikih.

2. Guru-guru yang mengajar di Madrasah Nizamiyyah adalah ulama-ulama Syari'ah seperti; Abu Ishaq al-Syarazi, al-Ghazali, alQazwaini, ibn al- Jauzi dan lain-lain. Tidak dikatakaan bahwa disana juga ada guru filsafat. maka Madrasah Nizamiyyah itu adalah madrasah syari'ah bukan madrasah filsafat.

3. Pendiri madrasah Nizamiyyah itu bukanlah orang-orang yang membela filsafat dan bukan pula orang yang membantu pembahasan filsafat.

4. Zaman berdirinya Madrasah Nizamiyyah bukanlah zaman keemasan filsafat melainkan zaman penindasan terhadap filsafat. ${ }^{14}$ 
Maka dari pembahasan-pembahasan diatas dapat kita pahami bahwa peranan pemerintah terhadap Madrasah Nizamiyyah salah satunya adalah dalam penentuan kurikulum dan staf pengajar atau guru Madrasah Nizamiyyah, dikarenakan pendirian Madrasah Nizamiyyah ini oleh penguasa dengan berbagai kepentingan politik maka mau tidak mau control pemerintah cukup kuat terhadap perjalanan dan proses belajar pendidikan di Madrasah Nizamiyyah. Sebagai contoh; adalah menunjukkan Abu Ishaq al-Syarazi sebagai staf pengajar pertama pada Madrasah Nizamiyyah oleh Nizam al-Mulk. Guru-guru ditunjuk sendiri tidak semberangan. mereka harus menganut aliran keagamaan yang sesuai dengan aliran keagamaan yang dianut oleh pemerintah yakni aliran Sunni. Sama halnya dengan kurikulum, jadi kontrol pemerintahan Dinasti Saljuq terhadap aktivitas pendidikan Madrasah Nizamiyyah tidak hanya sebatas penetuan kurikulum dan staf pengajar. Mereka juga turut menentukan kebutuhan anggaran biaya dan kepangkatan atau golongan staf-staf lainnya.

Kalau kita telusuri bahwa pendirian sebuah madrasah sebagai sebuah institusi pendidikan bila tidak dilandaskan kepada tujuan dari pendidikan itu sendiri, maka konsekwensi terhadap pendidikan tidak akan mendapat hasil yang baik. Seperti halnya Dinasti Saljuq yang mendominasi pendidikan hanya di sebagai alat menjadikan propaganda berkompetisi pengaruh dari idiologi politik yang pada saat itu, yaitu antara dinasti - dinasti pada waktu itu. Kemudian kurikulum juga didominasi dengan idiologi -politik yaitu sarat dengan muatan-muatan keagamaan, tanpa memasukkan kurikulum ilmu
- ilmu kealaman seperti; ilmu fisika, ilmu falak, ilmu pasti, kedokteran dan lain-lain. Karena ilmu yang harus dipejari bukan saja ilmu agama Islam tapi, keseluruhan dari ilmu-ilmu sehingga sianak didik dapat menguasai disamping ilmu agama Islam juga menguasai ilmu dan lainnya guna kelangsungan hidupnya yang seimbang antara dunia dan akhirat.

\section{PENUTUP}

Berdasarkan uraian yang telah penulis paparkan diatas, maka dapatlah diambil beberapa kesimpulan antara lain sebagai berikut :

1. Masa Dinasti Saljuq banyak terjadi kebangkitan pikiran yang pesat yang dasarnya telah dirintis oleh Nizamul Mulk wazir Alb Arsalan, wazir yang berilmu pengetahuan ini telah mendirikan sekolahsekolah atau madrasah-madrasah dengan menggunakan namanya; yaitu Nizamiyyah.

2. Pengetahuan dan pendidikan Islam yang telah didapat manusia sudah seyogyanya diorientasikan untuk kepentingan seluruh umat manusia. Karena sebaik-baik manusia adalah yang paling bermanfaat bagi manusia seluruhnya. Namun, tidak boleh dilupakan bahwa manusia juga hidup berdampingan dengan lingkungan alam sekitarnya.

3. Motif pendirian madrasah sebagai institusi pendidikan tidak murni bermotif kependidikan, ada motif politik dan idiologi dibalik pendirian madrasah oleh Dinasti Saljuq. Yakni sebagai alat propaganda tandingan untuk mengeliminasi pengaruh 
idiologi politik yang ada pada saat itu yang sewaktu-waktu dapat membahayakan kelangsungan kekuasaan Dinasti Saljuq. Yaitu idiologi Syiah yang dianut oleh Dinasti Buwaihi yang baru saja ditaklukkan oleh Dinasti Saljuq .

4. Kurikulum atau program pendidikan di madrasah di pengaruhi oleh idiologi yang dominan saat itu. yaitu idiologi Sunni. Kurikulum yang ada juga sangat sarat dengan muatan ilmu-ilmu keagamaan.

\section{DAFTAR PUSTAKA}

Al-Qardawi, Yusuf. Sunnah, Ilmu Pengetahuan dan Peradaban. Terj. Abad Badruzzaman. PT. Tiara Wacana. Yogyakarta. 2001.

Aly, Noer, Hery \& Suparta, Munzier. Pendidikan
Islam Kini dan Mendatang. CV. Triasco. Jakarta. 2003.

Syalabi, Ahmad, History of Education, Bairut: Dar al-Kashshaf ,1950.

Syalabi, A. Sejarah Kebudayaan Islam 3, Jakarta: Pustaka Al-Husna, 1993.

Yunus, Mahmud, Sejarah Pendidikan Islam, Jakarta: Hida Karya Agung, 1992.

http:/id.wikipedia, org/ wiki/berkas:seljuq emperi-locator-map.svg.

http:/id.wikipedia,org/ kesultanan, Saljuq raya \#cite-note-o.

http:hasan-rizal,wordpress,com/2009/10/21/ tafsirtarbawi-pendidikan-dalamperspektif al-qur\%/E2/80\%/99 an/

Suwito dan Fauzan, Sejarah Sosial Pendidikan Islam, Jakarta: Kencana,2005. 